\title{
Лiтература:
}

1. Andrade D.F., Tavares H.R, Valle R.C. Teoria da resposta ao Item: Conceitos e Aplicações. Sinape: SINAPE, 2000. 164 p.

2. Drasgow F., Nye C.D., Stark S., Chernyshenko O.S. Differential Item and Test Functioning / ed. Irwing, T. Booth, \& D. J. Hughes. The Wiley Handbook of Psychometric Testing. Manchester, UK: Wiley-Blackwell, 2018. P. 885-899.

3. Safanelli A. D., de Andrade D. F., Schimitt J., Cruz R. M. Evaluation of Ingressants in Distance Education Courses through the Item Response Theory. International Journal of Humanities and Social Science. 2018. № 7. P. 77-86. DOI:10.30845/ijhss.v8n7p.

4. Roberts J. S., Donoghue J. R. A general item response theory for unfolding unidimensional polytomous responses. Applied Psychological Measurement. 2000. № 24. P. 3-32.

DOI https://doi.org/10.30525/978-9934-26-039-1-95

\section{FEEDBACK CLASSIFICATION FOR UNDERGRADUATE TRANSLATORS' TRAINING AND ASSESSMENT}

\author{
Korol T. H. \\ Ph. D. in Pedagogical Studies, Associate professor, \\ Associate professor at the Department of Ukrainian, \\ Foreign Languages and Translation \\ Higher Educational Establishment of Ukoopspilka \\ «Poltava University of Economics and Trade» \\ Poltava, Ukraine
}

Undergraduate translators training in modern Ukrainian universities requires the adoption and application of new approaches to translation performance assessment. In this vein, social constructivist approach to translators' training and assessment seems to be rather promising and influential. Its provisions indicate the need in the arrangement of the efficient collaboration and interaction between the students and teachers in the process of translation performance. Feedback is considered to be part and parcel of such productive communication. In the context of translation training it involves any information delivered by an agent to a student about particular aspects of their translation product or process [3]. Transforming Shute's ideas [5, p. 154] to our research this information should cover the accuracy and 
adequacy of translation task performance, highlight particular translation mistakes and errors, outline correction options or provide appropriate guidelines for future learning and training activity. In our case, feedback content strongly correlates with the given source and expected target text properties, as well as reflects the accepted assessment criteria of translation product quality.

Initially, feedback concept was developed intensively in the frame of teaching foreign language writing (M. A. Erdoğan, M. M. Bless, F. V. Lim \& J. Phua, J. Boereboom \& K. Moore, D. Tsagari, etc.). As a result, available feedback classifications are also rooted in this direction of applied linguistics. The most extensive of them belong to R. Lyster \& L. Ranta [4] and M. Yang \& D. Carless [7].

The first classification involves six categories (explicit correction, recast, metalinguistic feedback / cue, elicitation, repetition and clarification request), distinguished on the basis of explicit / implicit and input-providing / outputprompting dimensions. Let us consider them in more details, comment on the appropriate delivery channel (oral or written) and opportunity to be applied in either translation or interpretation training.

1. Explicit correction is an explicit input-providing feedback type, when the assessor marks the produced inappropriate target utterance as an error / mistake and provides the correct ready-made target language structure. It is appropriate for both oral and written feedback delivery in translation and interpretation training.

2. Recast is an implicit input-providing feedback type, when ill-formulated target language units or inappropriately transferred source language ones are reformulated or expanded by the assessor, excluding student's errors or mistakes. This type of corrective feedback is considered to be one of the most widely and frequently used according to different sources [4; 2, p. 436], especially in case of oral feedback delivery. However, recasts appear to be inefficient in terms of motivating students to repair their mistakes and produce modified output [2, p. 437].

3. Metalinguistic feedback / cue is an explicit output-prompting feedback type, when the assessor provides the assessee with some kind of a comment or explanation that helps them to realize their error / mistake and formulate target language utterance properly or modify its previous output efficiently. This type of feedback appears to be productive in terms of students' self-correction skills development and provides positive impact upon their translation competence acquisition [1]. It can be given in both written and oral forms.

4. Elicitation is a half-explicit output-prompting feedback type, when the assessor indicates the error / mistake location and stimulates the assessee to 
formulate target language unit appropriately. Being combined with expressive intonation, this type of oral (rarely written) feedback can be rather fruitful in the context of interpretation training. However, in some situations, it can be used like some kind of a hint of proper structure to be used in translation training as well.

5. Repetition is an implicit output-prompting feedback type, when the assessor rewords the inappropriate target utterance produced by the assessee, inciting them to review and correct their target language utterance. It can be efficiently applied in oral mode being combined with proper stressing intonation.

6. Clarification request is an implicit output-prompting feedback type, when the assessor requires some kind of explanation from the assessee as for the target language structure produced, indicating some kind of problems, errors or mistakes. It can be presented in both written and oral forms while training both interpreters and translators.

To our mind, the feedback types described above intrinsically correspond to cognitive dimension of so-called 'feedback triangle' suggested by M. Yang \& D. Carless [7]. Apart from this aspect, it also contains socialaffective and structural ones [7, p. 287-289]. Combination of these feedback classifications allows us to provide more detailed taxonomy of feedback types to be applied in translators' training.

Social-affective dimension comprises role and function distribution in training environment as well as emotional aspect of the interaction of the involved parties [6]. According to these criteria, feedbacks can be classified in two different ways:

1) concerning the feedback agent or role distribution: teacher, peer, self and computer-generated;

2) concerning the emotional background involved:

- absolutely neutral, containing emotionless list of errors, mistakes and recommendations, if any are stipulated by the chosen cognitive feedback type;

- exclusively negative, stressing on and explicitly reprimanding students for their rude errors and mistakes made;

- exclusively positive, explicitly appraising students' successful translation solutions and neglecting mistakes made;

- emotionally diversified involving well-balanced explicit negative and positive evaluation of the translation task performed.

In its turn, structural dimension covers the organisation of feedback presentation in terms of timing, delivery channels, form, sequencing, expected 
responses as well as the ways of the assessment process management in general. In this case, feedbacks can be subdivided according to their:

1) timing: immediate / synchronous (usually computer-generated and impersonal or oral teacher ones in case of interpretation assessment); asynchronous, provided within a day, during a week, during two weeks, during an academic term, etc.;

2) delivery channels: oral (can be both group and individual); written (can be both group and individual); digital or computer-mediated (automatically produced by computer software; teacher feedback generated with the help of relevant computer utilities, for example, in the form of MS Word in-text notes or audio-recorded with the help of Read\&Write online Google application); combined (oral and written);

3) form and presentation:

- feedback volume (comment absence; extremely brief comment, formulated with the help of a couple of words / signs only; comparatively detailed; highly detailed);

- feedback language (Ukrainian (target one), English (source one), mixed (combination of English and Ukrainian, where appropriate));

4) expected response (feedback studies without any external response, feedback studies and self-reflection report preparation; feedback-based correction of the target text segment / feedback-based modification of the full target text; feedback-based correction of the target text preceded with a selfreflection report);

5) sequencing (single; multiple iterative but fixed in maximum quantity; multiple iterative unlimited in maximum quantity);

6) assessment management, which involves:

- grading issues (marked 'accepted /rejected', graded and feedback accompanied, only feedback provided).

- teacher control: low (no required obligatory response or resubmission), medium (optional response or resubmission) and high (obligatory response / corrected translation resubmission).

The feedback taxonomy presented above allows translation teachers to develop the feedback matrix array that takes into account varied factors such as students' individual peculiarities and training needs, types of translation or interpretation being practiced, training stage and translation competence level, etc. Their efficient combination and sequencing should improve students' learning outcomes, on the one hand, and enhance current assessment practices at domestic universities, on the other. 


\title{
References:
}

1. Ahmadi-Azad S. The effect of coded and uncoded written corrective feedback types on Iranian EFL learners' writing accuracy. Theory and Practice in Language Studies. 2014. Vol. 4(5). P. 1001-1007.

2. Brown D. The type and linguistic foci of oral corrective feedback in the L2 classroom: A meta-analysis. Language teaching research. 2016. Vol. 20(4). P. 436-458.

3. Hattie J., Timperley H. The power of feedback. Review of Educational Research. 2007. Vol. 77(1). P. 37-66.

4. Lyster R., Ranta L. Corrective feedback and learner uptake. Studies in Second Language Acquisition. 1997. Vol. 19. P. 37-66.

5. Shute V. J. Focus on formative feedback. Review of Educational Research, 2008. vol. 78(1). P. 153-189.

6. Värlander S. The role of students' emotions in formal feedback situations. Teaching in Higher Education. 2008. vol. 3(2). P. 145-156.

7. Yang M., Carless D. The feedback triangle and the enhancement of dialogic feedback processes. Teaching in Higher Education. 2013. Vol. 18(3). P. 285-297.

DOI https://doi.org/10.30525/978-9934-26-039-1-96

\section{SELF-OPTIMAZING LEARNING}

\author{
Laptinova Yu. I. \\ Candidate of Sciences in Philosophy, \\ Senior Teacher at the Department of Foreign Languages \\ Kharkiv National I. P. Kotlyarevsky University of Arts \\ Goncharova M. O. \\ Senior Teacher at the Department of Foreign Languages \\ Kharkiv National I. P. Kotlyarevsky University of Arts \\ Kharkiv, Ukraine
}

In recent years there has been a fundamental shift in language teaching, away from tenets of behaviorist psychology and structural linguistics and toward cognitive, and later, socio-cognitive psychology and more contextualized, meaning-based views of language [1]. This shift is generally known as the move from teacher-centered instruction to learner-centered or learningcentered instruction i.e. from the teacher to the student. Farrell and Jacobs list 